\title{
Long-Term Effects of Sectioning the Olivocochlear Bundle in Neonatal Cats
}

\author{
Edward J. Walsh, ${ }^{1}$ JoAnn McGee, ${ }^{1}$ Sandra L. McFadden, ${ }^{1}$ and M. Charles Liberman ${ }^{2,3}$ \\ ${ }^{1}$ Boys Town National Research Hospital, Omaha, Nebraska 68131, 2Eaton-Peabody Laboratory, Massachusetts Eye and \\ Ear Infirmary, Boston, Massachusetts 02114, and ${ }^{3}$ Department of Otology and Laryngology, Harvard Medical School, \\ Boston, Massachusetts 02115
}

\begin{abstract}
The olivocochlear bundle (OCB) was cut in neonatal cats to evaluate its role in the development of normal cochlear function. Approximately 1 year after deefferentation, acute auditory nerve fiber (ANF) recordings were made from lesioned animals, lesion shams, and normal controls. The degree of deefferentation was quantified via light microscopic evaluation of the density of OCB fascicles in the tunnel of Corti, and selected cases were analyzed via electron microscopy. In the most successful cases, the deefferentation was virtually complete. ANFs from successfully lesioned animals exhibited significant pathophysiology compared with normals and with other animals in which the surgery failed to interrupt the OCB. Thresholds at the characteristic frequency (CF), the frequency at which ANFs are most sensitive, were elevated across the CF range, with maximal effects for CFs in the $10 \mathrm{kHz}$ region. Frequency threshold
\end{abstract}

or tuning curves displayed reduction of tip-to-tail ratios (the difference between CF and low-frequency "tail" thresholds) and decreased sharpness of tuning. These pathological changes are generally associated with outer hair cell $(\mathrm{OHC})$ damage. However, light microscopic histological analysis showed minimal hair cell loss and no significant differences between normal and deefferented groups. Spontaneous discharge rates (SRs) were lower than normal; however, those fibers with the highest SRs remained more sensitive than those with lower SRs. Findings suggest that the interaction between $\mathrm{OC}$ efferents and OHCs early in development may be critical for full expression of active mechanical processes.

Key words: efferent; olivocochlear; cochlea; development; superior olivary complex; hearing; auditory; deefferentation
In the adult mammal, the cochlea receives two types of efferent innervation from the superior olivary complex (Warr, 1992; Guinan, 1996). One division of this olivocochlear (OC) pathway, the medial OC (MOC) system, projects to the outer hair cells (OHCs) via myelinated fibers, where it gives rise to large, axosomatic terminals (Warr, 1975; Guinan et al., 1983). The unmyelinated fibers of the lateral OC (LOC) system project mainly to afferent dendrites in the neuropil below inner hair cells (IHCs). The functional significance of the LOC system is very poorly understood. The function of the MOC system also remains controversial; however, it is clear that MOC fibers respond to sound and constitute the effector arm of a binaural sound-evoked reflex. Activation of the MOC system (1) diminishes cochlear sensitivity, presumably by modulating the OHC contribution to active cochlear mechanics (Mountain, 1980; Siegel and Kim, 1982; Brown et al., 1983; Guinan, 1986; Murugasu and Russell, 1996); and (2) protects the ear from acoustic overstimulation (Rajan, 1988a,b; 1995), apparently via effects on intracellular calcium concentrations (Reiter and Liberman, 1995; Sridhar et al., 1995). MOC

\footnotetext{
Received Aug. 27, 1997; revised Feb. 18, 1998; accepted Feb. 27, 1998.

This work was supported by National Institute of Deafness and Other Communication Disorders Grants DC00215, DC00034, and DC00188. We acknowledge the dedicated efforts of R. Felner, B. Flegas, J. Jenkins, M. Kliment, T. Krivohlavek, J. Lackey, Y. Liu, T. Molloy, L. Song, and Y. Zhang for participating in the postsurgical care of lesioned animals and the work of W. Y. Gao and D. F. O'Grady in the histological preparation and analysis.

Correspondence should be addressed to Edward J. Walsh, Boys Town National Research Hospital, Developmental Auditory Physiology Laboratory, 555 North 30th Street, Omaha, NE 68131.

S. L. McFadden's present address: Center for Hearing and Deafness, State University of New York at Buffalo, Buffalo, NY 14214.

Copyright (C) 1998 Society for Neuroscience $0270-6474 / 98 / 183859-11 \$ 05.00 / 0$
}

reflex effects on cochlear sensitivity also provide a feedback gain control that aids in the discrimination of stimulus transients in a noisy environment (Winslow and Sachs, 1988; Kawase and Liberman, 1993; May and McQuone, 1995).

Chronic cochlear deefferentation in adult mammals has been studied extensively, including its effects on auditory performance (Dewson, 1968; Trahiotis and Elliott, 1970; Igarashi et al., 1972; Scharf et al., 1994; May and McQuone, 1995), as well as auditory neurophysiology (Liberman, 1990) and susceptibility to acoustic injury (Handrock and Zeisberg, 1982; Liberman and Gao, 1995; Zheng et al., 1997a,b). Indeed, results of such studies underlie most speculations as to olivocochlear bundle (OCB) function. In contrast, the effects of neonatal chronic cochlear deefferentation are poorly understood. In an anatomical study, Pujol and Carlier (1982) sectioned the OCB in neonatal cats and reported that the afferent innervation of OHCs failed to develop normally. They suggested that the normal arrival of MOC terminals at the OHCs during postnatal development is necessary to effect the pruning of exuberant afferent contacts in the $\mathrm{OHC}$ area. In a physiological study, Walsh and McGee (1997) showed that transection of the OCB in neonatal cats eliminates the rhythmic responses normally seen in the spike trains of immature auditory neurons and suggested that the OCB may play a role in culling exuberant contacts between IHCs and their afferents (Walsh and McGee, 1987, 1988). Both results are consistent with the idea that the OCB plays a role during cochlear development; however, the long-term functional effects of neonatal deefferentation have never been investigated.

In neonatal cats, the cochlear epithelium is incompletely developed and essentially nonresponsive to sound (Walsh and McGee 
1986; Walsh and Romand, 1992). MOC fibers are beginning to invade the cochlea; however, they initially contact IHCs and afferent dendrites exclusively (Pujol and Abonnenc, 1977; Pujol et al., 1978, 1979; Lenoir et al., 1980; Shnerson et al., 1982; Jones and Eslami, 1983; Ginzberg and Morest, 1984; Simmons et al., 1990, 1996). OHCs are devoid of OC contacts at this stage (Pujol et al., 1978, 1979), and it is not clear that the LOC innervation has yet arrived. Thus, in a neonatally deefferented cat, the organ of Corti will have had minimal contact with the OC system. During the following 3 postnatal weeks, cochlear output becomes adultlike, roughly coincident with the development of an adult-like projection of the OCB onto cochlear targets (Pujol et al., 1978). To determine the long-term functional consequences of neonatal OCB disruption on response properties of auditory nerve fiber (ANFs), we transected the pathway in neonates and evaluated the response properties of ANFs $\sim 1$ year later. The consequences were profound, affecting sensitivity, frequency selectivity, and spontaneous discharge rate (SR).

\section{MATERIALS AND METHODS}

Cats were used as experimental animals. The care and use of all animals were in accordance with the guidelines of the animal welfare committee of Creighton University and the Boys Town National Research Hospital.

\section{Deefferentation surgery and postsurgical care}

Animals were prepared for sterile surgery by administration of penicillin $(15,000 \mathrm{U} / \mathrm{kg}$, i.m. $)$ and atropine sulfate $(0.05 \mathrm{mg} / \mathrm{kg}$, i.m. $)$. Surgical levels of anesthesia were achieved with sodium pentobarbital $(20-40 \mathrm{mg} / \mathrm{kg}$, i.p.). Supplemental anesthesia was delivered as required (intraperitoneal pentobarbital at $10 \%$ of original dose or inhaled isofluorane at $0.5-2 \%$ mixed with $\mathrm{O}_{2}$ ) to maintain areflexia. After full anesthetization, the dorsal and posterior aspect of the skull was exposed, and a circular craniectomy into the posterior fossa $(\sim 5 \mathrm{~mm}$ in diameter) was made by rongeuring occipital bone between the foramen magnum and the nuchal crest. Dura mater was incised, and the cerebellum was gently elevated, exposing the floor of the fourth ventricle. Guided by surface landmarks on the dorsal aspect of the brainstem, a knife cut was made to sever the OCB. Midline cuts, designed to cut the crossed OCB bilaterally, were made along the saggital plane at a depth of $\sim 2 \mathrm{~mm}$; and off-midline cuts, $\sim 4 \mathrm{~mm}$ in depth, were made along the sulcus limitans with the knife angled $\sim 45^{\circ}$ from vertical in the dorsomedial to ventrolateral direction. The cerebellum was released, dural flaps were reapposed, and sterile Gelfoam was placed over the craniectomy. Muscles and skin flaps were reapposed and sutured. Some animals, particularly in combined midline and off-midline transections, stopped normal breathing immediately after the cut was made. In these cases, artificial ventilation was applied for a few minutes, and doxapram hydrochloride was administered (10-25 $\mathrm{mg} / \mathrm{kg}$, i.m.) to stimulate respiration.

After cleansing of the incision with Betadine and topical application of Neosporin, animals were transferred to an incubator and continuously monitored pending recovery from anesthesia. Postsurgical monitoring included auscultation of heart and lung-airway sounds, fluid replacement (subcutaneous lactated Ringer's solution as needed), and somatosensory stimulation, including periodic stimulation of the urogenitoanal area to promote normal alimentary canal function. Animals were tube fed through an intragastric tube every $2 \mathrm{hr}$ (5\% dextrose initially and gradually weaned onto a milk replacement formula). As recovery progressed, the interval between feedings was lengthened, and animals were returned to the mothers as soon as possible between feedings to promote maternal care of kittens. Once they were gaining weight independent of supplemental feedings, subjects were no longer tube fed. Butorphanol $(0.4-0.8$ $\mathrm{mg} / \mathrm{kg}$, s.c. or i.m.) was administered as needed at $6-8 \mathrm{hr}$ intervals if there was any evidence of pain or distress postsurgically, and penicillin $\left(15,000 \mathrm{U} \cdot \mathrm{kg}^{-1} \cdot \mathrm{d}^{-1}, \mathrm{i} . \mathrm{m}\right.$.) was administered prophylactically for $5 \mathrm{~d}$ after surgery.

\section{ANF recordings}

Surgical preparation. Animals were anesthetized with sodium pentobarbital $(40 \mathrm{mg} / \mathrm{kg}$, i.p.), and an intravenous catheter was typically inserted to allow supplemental pentobarbital to be administered as needed to maintain a surgical level of anesthesia. Atropine sulfate was administered before surgery $(0.05 \mathrm{mg} / \mathrm{kg}$, i.m.). A tracheotomy was performed, and the animals were ventilated, if necessary, using a small-animal respirator. Body temperature was maintained at $\sim 37.5^{\circ} \mathrm{C}$ using a thermostatically controlled heating blanket. The pinna and external meatus were resected bilaterally to the level of the tympanic ring, allowing visualization of tympanic membranes, and a small hole was bored in each bulla through which a ventilation tube was inserted. The occipital bone was surgically exposed, and the animal was positioned in a stereotaxic apparatus. The posterior fossa was opened, and the cochlear nucleus and auditory nerve complex were exposed by aspirating the cerebellum. Recordings were made for $1-5 \mathrm{~d}$. During this period, the animal's heart rate and respiratory rate were monitored, and fluids were replaced regularly. Penicillin was administered to animals maintained longer than $2 \mathrm{~d}(15,000$ $\mathrm{U} \cdot \mathrm{kg}^{-1} \cdot \mathrm{d}^{-1}, \mathrm{i} . \mathrm{m}$.). At the end of the recording session, animals were overdosed with pentobarbital and killed by intracardiac perfusion of fixative. All animals participating in the acute phase of the experiment were between 1 and 14 postnatal days of age (P1 and P14) at the time of surgery; all but two animals were operated on between the ages of P1 and $\mathrm{P} 5$. ANF recordings were made from adults ranging in age from 2 months to 2 years; the average age was $\sim 1$ year. Results included findings from all animals participating in the acute recording phase of the experiment for which corresponding histological data were available.

Acoustic system and calibration. Acoustic signals were synthesized digitally, amplified with a low-distortion amplifier, digitally shaped and gated, and passed through an antialiasing filter. Tone bursts were symmetrical and linearly ramped with $5 \mathrm{msec}$ rise-fall times. Stimuli were attenuated using custom-built attenuators with $1 \mathrm{~dB}$ resolution. The stimulus generation system was controlled via an IBM-compatible 486 personal computer, fully integrated with data acquisition by an interface to a Cambridge Electronics peripheral device (CED 1401+) used for event timing and analog-to-digital conversion. Stimuli were delivered to the ear via dynamic earphones (Beyerdynamic DT-48) coupled to the ear with a speculum sealed in the external canal. The acoustic system was calibrated in vivo before each recording session with a 0.5 inch condenser microphone (Brüel and Kjær 4134) inserted into a probe-tube assembly coupled to the earphone speculum. Frequencies were sampled at 10 points per octave between 0.1 and $50 \mathrm{kHz}$. Previously calibrated values for the probe-tube transfer function were used to correct the microphone output to the sound pressure level near the tympanic membrane.

Recording and data collection techniques. Animals were placed within a double-walled, sound-attenuating chamber for the duration of the experiment. Glass micropipettes, filled with $2 \mathrm{M} \mathrm{KCl}(15-30 \mathrm{M} \Omega$ ), were used to record single-fiber activity. Recorded voltages were fed to a preamplifier, viewed on a storage oscilloscope, and delivered to an audio monitor. Event times for individual action potential discharges were digitized using the gate output of an oscilloscope and transferred to the event timer of the CED $1401+$. Spike times were measured relative to the onset of the stimulus and digitized on-line with $10 \mu \mathrm{sec}$ resolution. Neural activity, synchronization pulses, stimulus output, and voice commentary were also recorded on videotape. Auditory nerve fibers were identified based on action potential shape and response latencies. For each fiber isolated, the spontaneous discharge activity was recorded for a minimum of $15 \mathrm{sec}$. A frequency tuning curve was then collected using $50 \mathrm{msec}$ tone bursts presented 10/sec using an automated procedure modified from that of Liberman (1978), which maps an isorate contour corresponding to a 20 spikes/sec increase over SR. This algorithm tests frequencies from 45 $\mathrm{kHz}$ to $100 \mathrm{~Hz}$ with resolution of 16 points per octave.

Differences between sham-operated and deefferented animals were assessed across a characteristic frequency ( 0.5 octave intervals) by twoway ANOVA. The Tukey test was used for multiple comparisons. Frequencies $<0.951$ and $>21.527 \mathrm{kHz}$ were omitted from the statistical analyses because of small and irregular sample sizes, and differences were considered significant at $p<0.001$. The relationship between tip-to-tail ratio and the density of efferent projections (see Figure 5) was assessed by linear regression using Pearson's correlation coefficient and was found to be significant at the $p=0.002$ level.

\section{Histological evaluation}

After physiological recordings, the cochleas were prepared as described by Liberman and Gao (1995). Briefly, cochleas were fixed by intralabyrinthine perfusion of a solution of buffered aldehydes. After $12 \mathrm{hr}$ of post-fixation, the cochleas were osmicated, dehydrated in graded ethanols followed by propylene oxide, and embedded in epoxy resins. After polymerization, the temporal bone was drilled away, the cochlear duct was dissected into pieces $\sim 1 \mathrm{~mm}$ in length, and the pieces were re- 
embedded in epoxy resins. Each plastic-embedded piece was thinned with sanding disks and glued to a microscope slide, allowing the entire sensory epithelium to be viewed as a surface preparation with a light microscope. Hair cell counts (cytocochleograms) and analysis of efferent innervation were performed by an observer blind to physiological results and surgical treatments. Cochlear distance was measured using a drawing tube, and the conversion from cochlear location to characteristic frequency $(\mathrm{CF})$ was made according to a cochlear frequency map for the cat (Liberman, 1982). General techniques for analysis of hair cell populations in plastic-embedded surface preparations were as described by Liberman and Dodds (1984).

To assess the degree of deefferentation, the diameters of all fascicles crossing the tunnel of Corti were measured at the level of the tunnel spiral bundle at a position $\sim 10 \mu \mathrm{m}$ from the inner pillar feet. These measurements were based on tracings made with a drawing tube at an overall magnification of $2200 \times$ using differential interference contrast microscopy. The traced diameters were digitized on a data tablet and converted to micrometers. The summed fascicular diameter in each dissected piece of the organ of Corti was divided by the length of that piece to provide a quantitative estimate of the integrity of the $\mathrm{OHC}$ efferent innervation. This metric of average fascicular diameter has been shown to correlate well with the volume of MOC terminals remaining on OHCs in partially deefferented guinea pigs (Liberman and Gao, 1995). The metric is based on fiber diameter rather than fiber counts, because single, tracer-filled MOC neurons show large variation in caliber in the tunnel-crossing area, and fiber caliber is closely correlated with the total volume of OHC terminals generated (Brown, 1987). In selected cases, pieces of the organ of Corti were remounted for ultrathin sectioning and examination in the electron microscope. Serial section ribbons were collected on Formvar-coated slot grids and stained with uranyl acetate and lead citrate in preparation for ultrastructural observation.

\section{RESULTS}

The present results are based on single-fiber recordings from the auditory nerve in 21 adult cases that underwent neonatal deefferentation surgery. These 21 cases were harvested from 14 animals, because recordings were sometimes obtained from both sides of an individual animal. As described in Materials and Methods, two types of lesions were attempted: a midline incision to cut the crossed OCB to both sides or a side cut to interrupt the entire OC pathway to one ear. Sometimes only one lesion was made, and sometimes both midline and side cuts were made in a single animal; however, bilateral side cuts were never attempted. As described below, in Histological evaluation, lesions were successful in about half of the animals. In the analysis that follows, Auditory nerve recordings, we consider the unsuccessful lesions to be sham operations, and we compare the physiological results in the lesion group versus the sham group.

\section{Histological evaluation}

Assessment of deefferentation

The success of the OCB lesion was assessed in each case by measuring the summed diameter (expressed per millimeter of cochlear length) of all of the MOC fascicles crossing through the middle of the tunnel of Corti at the level of the tunnel spiral bundle. These fascicles are clearly visible in osmium-stained surface preparations, when viewed with differential interference light microscopy, and such a metric has been shown to provide a good approximation of the volume of MOC terminals remaining on the OHCs (Liberman and Gao, 1995).

The results of the MOC fascicle measurements for all of the ears in the present study are summarized in Figure 1. In both parts of Figure 1, data from "control" ears (filled squares) represent measurements made (1) in cases in which no lesion was made in the brainstem or (2) from the opposite ears of cases in which only a unilateral side cut was attempted. Based on these control measurements, data from the lesioned cases were divided into "successful" and "unsuccessful" cuts; unsuccessful midline or
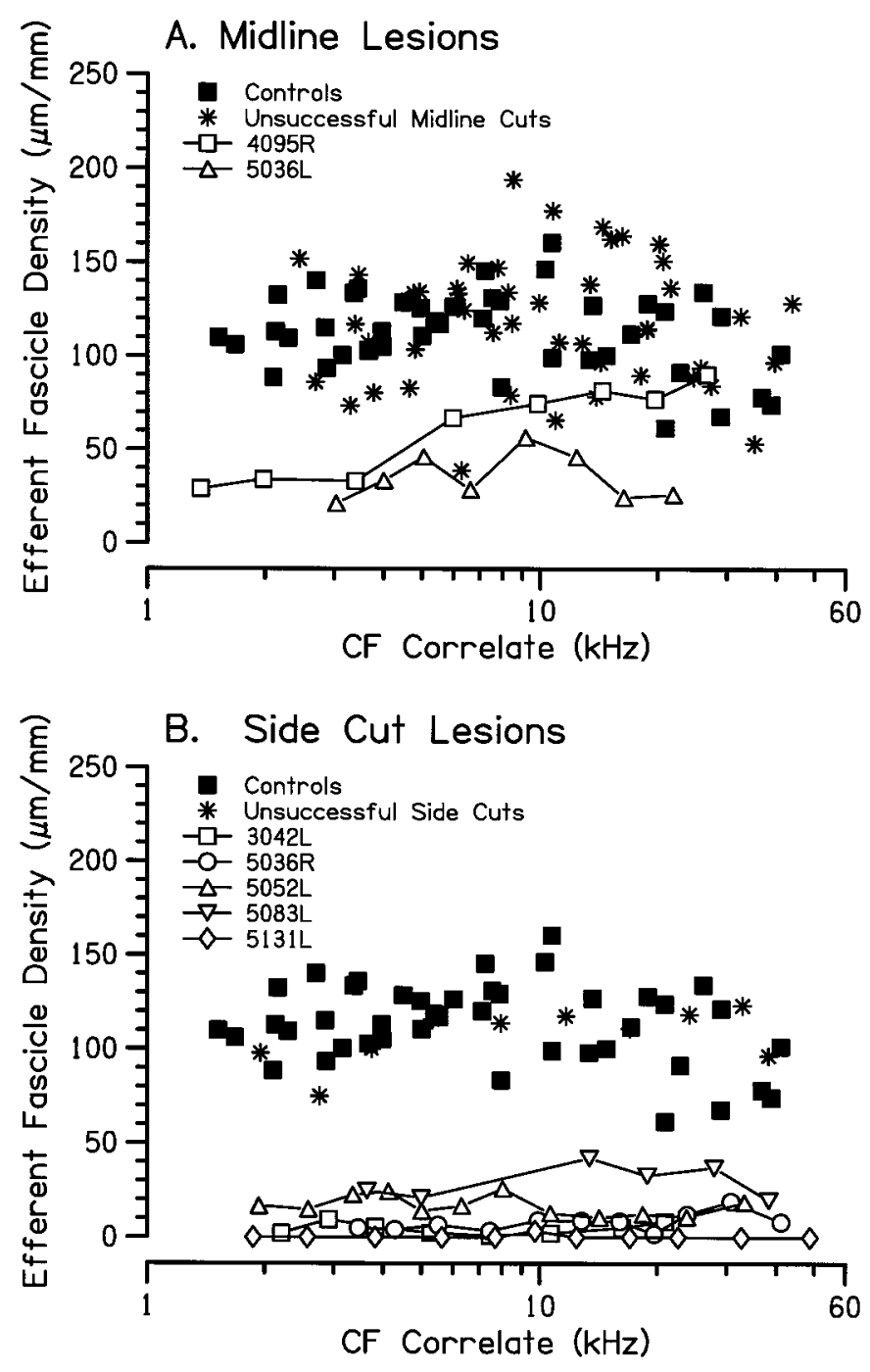

Figure 1. Measure of efferent fascicle density in the tunnel of Corti used as an assay of the success of the OC lesions for attempted midline incisions $(A)$ and attempted complete unilateral lesions $(B)$. Fascicle density is defined as the summed diameter of all tunnel-crossing MOC fascicles averaged over each millimeter of the cochlear partition. Cochlear location is converted to a CF correlate according to a cochlear frequency map for the cat (Liberman, 1982). The control data (filled squares) are the same in both $A$ and $B$; they represent measures taken from animals in which no brainstem cuts were made and those from the sides opposite to a unilateral lesion. See Results for further details.

side cut cases are plotted as asterisks in Figure 1, $A$ and $B$, respectively.

Based on the known anatomy of the OC system, a completely successful midline cut should eliminate approximately two-thirds of the efferent innervation of the $\mathrm{OHCs}$, because one-third of the MOC pathway originates ipsilaterally, and only the crossed OCB is cut at the midline (Warr and Guinan, 1979; Warr, 1992). In this context, it would appear that the midline cut in case $5036 \mathrm{~L}$ was completely successful, whereas the success of case $4095 \mathrm{R}$ was partial (Fig. 1A). (Off-midline lesions were attempted contralaterally in each of these cases; however, the assessment of the midline cut success was made independently, based on ipsilateral histological findings.) The known anatomy suggests that the LOC system should be largely intact in these cases (midline cuts); 
however, no attempt was made in these cases to evaluate the efferents in the IHC area.

The analysis in Figure $1 B$ suggests that in five cases the side cuts were largely successful. In three of these cases (3042L, 5036R, and 5131L), the deefferentation appears virtually complete. In the other two (5083L and 5052L), more MOC fascicles remain, although at least two-thirds of the MOC system appears to be eliminated. In some of these side cut cases, selected regions of the organ of Corti were evaluated in the electron microscope (EM) to assess the status of the LOC innervation and/or to verify the degree of deefferentation of the OHCs. With respect to LOC status, the EM analysis showed complete absence of the inner spiral bundle under the IHCs in each of the three cases classified as complete based on the tunnel fascicle analysis (3042L, 5036R, and $5131 \mathrm{~L})$. On the control side of one of these cases (3042R), EM analysis showed a normal inner spiral bundle. The EM analysis of the OHCs focused on the $12 \mathrm{kHz}$ region of the cochlea in cases $3042 \mathrm{~L}, 5036 \mathrm{R}$, and $5131 \mathrm{~L}$; in a semiserial section analysis of at least $10 \mathrm{OHCs}$ from each of the three rows in each of these cases, we failed to find a single efferent terminal. Thus, the EM analysis provides strong support for the view that the deefferentation of both LOC and MOC systems is very nearly complete in all of these cases.

\section{Cochlear histopathology}

Cytocochleograms, i.e., complete counts of hair cell loss as a function of cochlear location, were generated for all of the successful side cut cases in the present study and for a randomly chosen subset of the unsuccessful lesions. As shown in Figure 2, there were no significant differences in the degree or pattern of hair cell loss in the two groups. IHCs were almost all present in both groups. For cochlear regions outside the basal one-fifth (i.e., for $\mathrm{CF}$ regions $<15 \mathrm{kHz}$ ), OHC loss was insignificant. In the basal turn, there were significant lesions of all three OHC rows in some animals from each group. Such a degree of OHC loss is not common in normal cats, i.e., those that have not undergone brain surgery as neonates. However, the data in Figure 2 suggest that these basal turn lesions are not correlated with the success of the deefferentation.

\section{Auditory nerve recordings \\ Thresholds at $C F$}

Recordings from single ANFs revealed that sensitivity to acoustic stimulation was significantly reduced in successfully deefferented animals. This threshold elevation was significant when compared with either normal controls (that did not undergo neonatal surgery) or with those operated animals in the present study with unsuccessful OC lesions.

Scatter plots of thresholds at CF for six operated animals are shown in Figure 3, each of which is compared with the data from the same unoperated control (open squares). Examination of these six cases clearly shows that, whereas thresholds at the CF are close to normal in a sham-operated animal (4066R) and an unsuccessful midline cut case (3040R), thresholds are significantly elevated in the successful midline cut case $(5036 \mathrm{~L})$ and in each of the three successful side cut cases $(5131 \mathrm{~L}, 5036 \mathrm{R}$, and 5083L).

The trends suggested by the individual cases shown in Figure 3 are maintained when data from all animals in the present study are considered. In Figure $4 A$, all operated cases are separated into two groups according to the success of the lesion, as described above (and illustrated in Fig. 1). This plot of mean
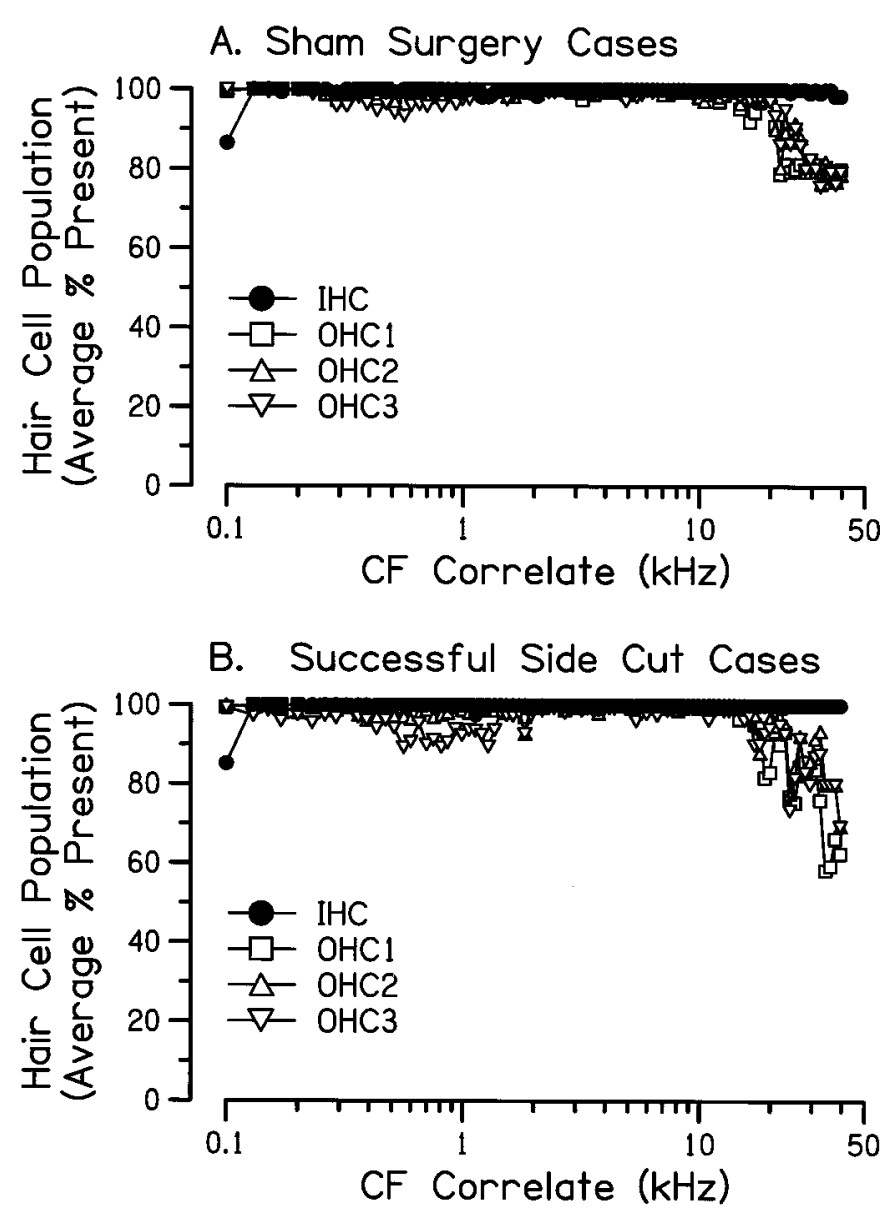

Figure 2. Average hair cell loss (cytocochleograms) for five unsuccessful lesion cases $(A)$ and five successful side cuts $(B)$. In each, the average percent of hair cells remaining in the inner hair cell $(I H C)$ row and the three outer hair cell $(O H C)$ rows is plotted as a function of cochlear location expressed as CF correlate as in Figure 1. The five cases used in $A$ were $3040 \mathrm{R}, 3042 \mathrm{R}, 5053 \mathrm{~L}$, and $5053 \mathrm{R}$; those for $B$ were $3042 \mathrm{~L}, 5036 \mathrm{R}$; $5052 \mathrm{~L} ; 5083 \mathrm{~L}$, and $5131 \mathrm{~L}$.

thresholds $( \pm$ SEM) for high-SR fibers clearly shows the strong effect of successful deefferentation on ANF thresholds. Mean threshold differences were in the range of $20 \mathrm{~dB}$, although differences exceeding $60 \mathrm{~dB}$ were observed. The largest differences are seen in ANFs from the $4.0-8.0 \mathrm{kHz}$ regions of the cochlea.

\section{Tip-to-tail ratios}

Previous studies of ANF response in animals with cochlear abnormalities have shown that changes in sensitivity to near-CF tones are not always associated with threshold elevations off the CF (Liberman and Kiang, 1978; Dallos et al., 1980; Schmiedt and Zwislocki, 1980; Schmiedt et al., 1980). Tuning curves from neonatally deefferented animals generally showed elevations of the sharply tuned "tip" without concomitant elevations of the broad low-frequency "tail." Average tail thresholds (i.e., the minimum threshold of the tuning curve tail) are similar in experimental and control cases across the CF range (Fig. 4D).

One metric of tuning curve shape that has been applied in the past to the study of auditory nerve pathophysiology is the "tipto-tail ratio," i.e., the difference between the threshold at $\mathrm{CF}$ and the tail threshold (Kiang et al., 1970). As shown in Figure 4B, average tip-to-tail ratios in successfully deefferented animals are 


\section{Unoperated Operated}

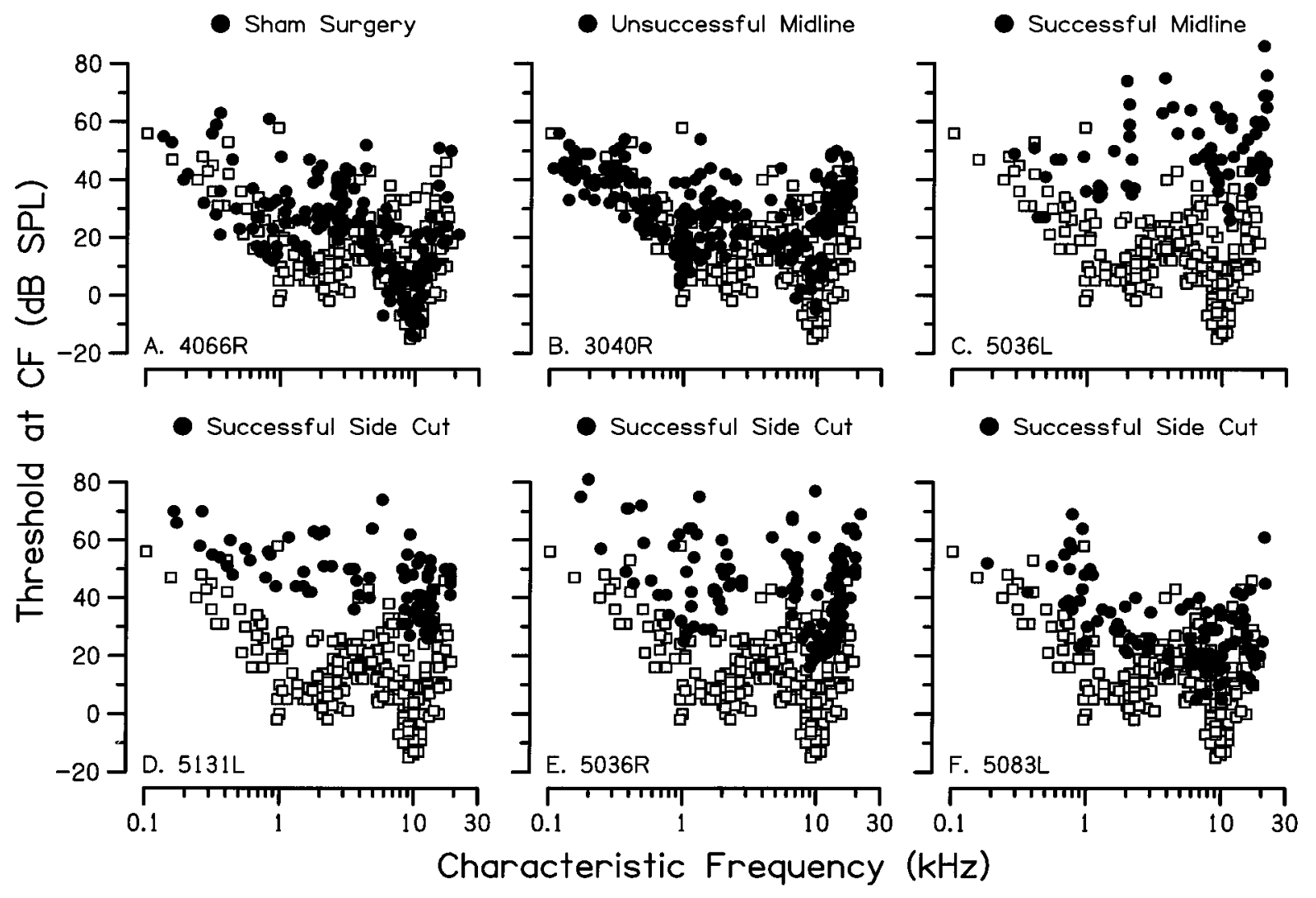

Figure 3. Thresholds at the characteristic frequency $(C F)$ of auditory nerve fibers are plotted as a function of CF for six different animals, each compared with the thresholds seen for an unoperated control animal of similar age. Each point represents data from a different fiber. Case numbers and the nature and success of the lesion are indicated.

significantly reduced across most of the $\mathrm{CF}$ range with respect to their operated cohorts in which the OCB remained intact.

The relation between mean degree of deefferentation and mean tip-to-tail ratio is shown on a case-by-case basis in Figure 5. For each data point, the degree of deefferentation was averaged across the $\mathrm{CF}$ correlate, and the mean tip-to-tail ratios were obtained by averaging values $>5 \mathrm{kHz}$. This relationship is relatively well characterized by a straight line with slope of $0.21(r=$ $0.702 ; p=0.002)$.

\section{Sharpness of tuning}

In addition to diminished sensitivity, the sharpness of tuning was also significantly decreased in successfully deefferented animals. As was the case for CF thresholds, the $Q_{10}$ metric of sharpness of tuning (the $\mathrm{CF}$ divided by the bandwidth at $10 \mathrm{~dB}$ above threshold) appears similar in the sham-operated case and the unsuccessful midline cut case relative to the unoperated control case. Group data from individual cases are shown in Figure 6 for six operated animals, the same six cases for which CF thresholds were illustrated in Figure 3, and although difficult to resolve in a scatter plot format, the sharpness of tuning was significantly reduced in the successful lesion cases and especially in the successful side cuts. The overall effect of neonatal deefferentation is clearly illustrated in the average group data (for high-SR fibers) shown in Figure $4 C$. Significant differences were observed for $\mathrm{CF}$ regions above $\sim 5 \mathrm{kHz}$.

\section{Spontaneous discharge rates}

A previous study of chronic deefferentation in adult cats (Liberman, 1990) suggested that one of the effects of such surgery in adults was a significant decrease in SRs. The averages of spontaneous rates for fibers with $\mathrm{SR}$ of $>18$ spikes/sec from adult cats deefferented as infants, as shown in Figure 7, suggests that there is a significant lowering of mean SRs in the successfully deefferented side cut cases, and that the largest effects are restricted to the basal two-thirds of the cochlea, i.e., CFs of $>1 \mathrm{kHz}$. As seen from the histograms in Figure 8, samples of ANFs (CFs of $>1$ $\mathrm{kHz}$ ) in normal ears show a fundamentally bimodal distribution of SRs, with a high-rate peak (mode of $\sim 50$ spikes/sec) separated from a low-rate peak by a gap at rates of 10-30 spikes/sec. As illustrated by the individual cases in Figure 8, the SR distribution was often compressed in neonatally deefferented animals. It is also clear from the cases shown in Figure 8 that not all successful side cuts showed severe compression of the SR distribution (e.g., 5131L).

The long-standing observation that low-SR fibers in normal ears tend to have higher thresholds than high-SR fibers (Liberman, 1978; Liberman and Kiang, 1978) and significantly greater LOC innervation than high-SR fibers (Liberman et al., 1990) has suggested that the LOC innervation might play a role in the development or maintenance of the striking SR-based differences in ANF response. Data from successfully deefferented cases, including ones for which EM analyses have suggested that the 


\section{Sham Surgery Cases Successful Midline or Side Cuts}

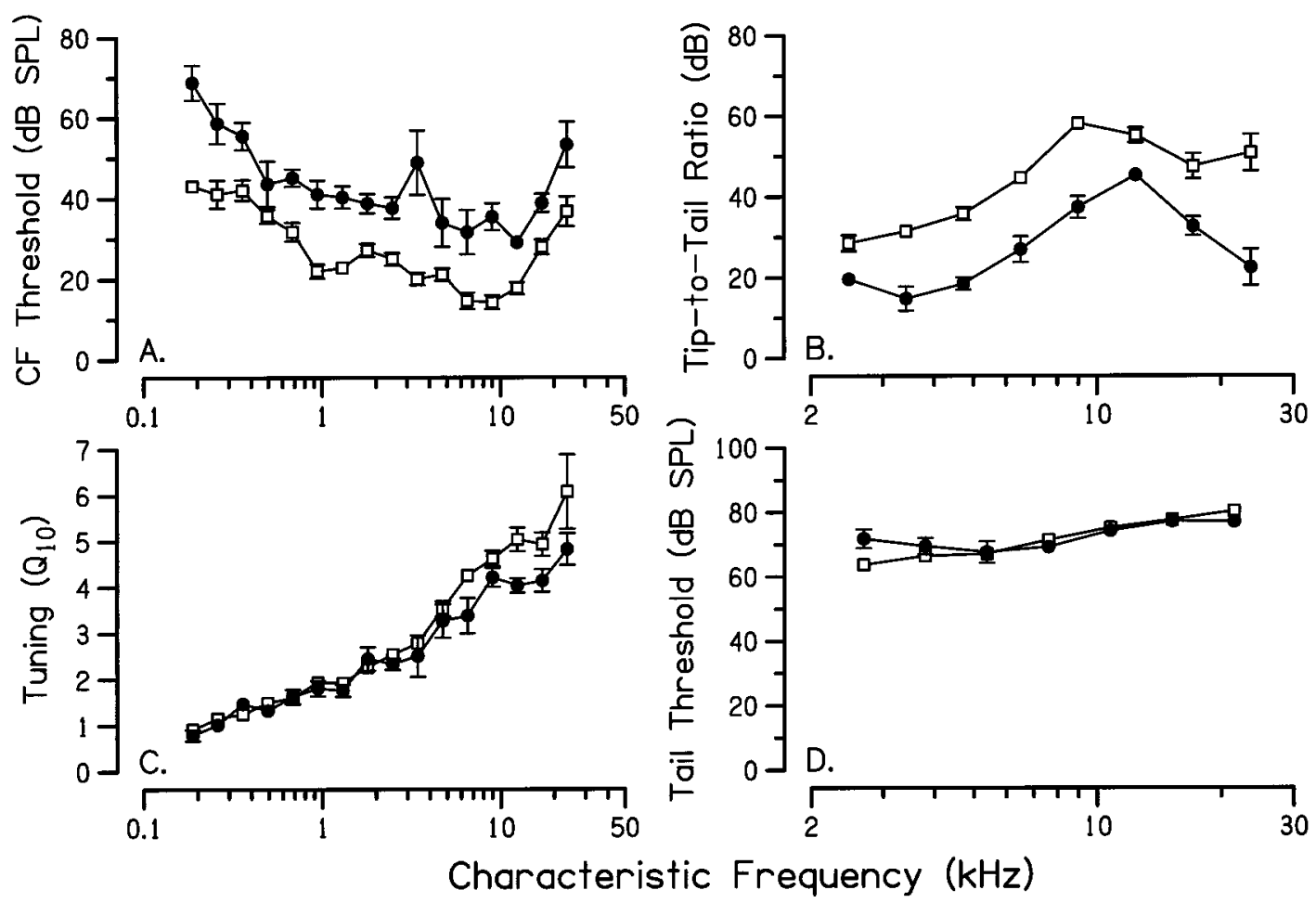

Figure 4. Comparison of average physiological results for all successfully deefferented animals and those animals undergoing the same surgical procedures in which the cut failed to transect the OCB. Values for all parts are extracted from tuning curves: thresholds at CF $(A)$, tip-to-tail ratio $(B)$, tuning sharpness $(C)$, and tail thresholds $(D)$. Tip-to-tail ratio $(B)$ is defined as the difference between threshold at $\mathrm{CF}$ and the tail threshold. $Q_{10}(C)$ is defined as the CF divided by the tuning curve bandwidth at $10 \mathrm{~dB}$ above threshold. Tail threshold $(D)$ is defined as the minimum threshold on the broadly tuned tail of the tuning curve. For each part, all high-SR fibers from all of the available cases are divided, according to CF, into $\sim 0.5$-octave bins; values for all fibers are averaged and displayed \pm SEM.

LOC and MOC systems were completely eliminated in the perinatal period, clearly show that an intact OC is not necessary for the normal development of both high- and low-SR fibers and normal correlation between SR and threshold. As shown in Figure 9, even though all of the CF thresholds are elevated in this deefferented ear from an animal with a complete loss of both MOC and LOC systems, it remains the case that the most sensitive fibers at each CF region are those with the highest SRs, and the least sensitive are those with the lowest SRs.

\section{DISCUSSION}

\section{Cochlear structure and function near the time of deefferentation}

All successful deefferentations in the present study were performed from P2 to P4, a developmental period during which significant histological and physiological changes occur in the cochlea (for review, see Walsh and Romand, 1992).

Major developmental changes that occur within the middle and upper turns of the cochlea during this period include the secretion of the tectorial membrane along a modiolostrial gradient; the formation of perilymphatic and endolymphatic chambers, including the tunnel of Corti and space of Nuel; general maturation of electroanatomical characteristics, including the stria vascularis and Reissner's membrane; as well as the overall acquisition of adult-like dimensions and fibrous content of the basilar membrane and Kolliker's organ (Pujol and Marty, 1970; Lindeman et al., 1971; Kraus and Aulbach-Kraus, 1981; Roth and Bruns,

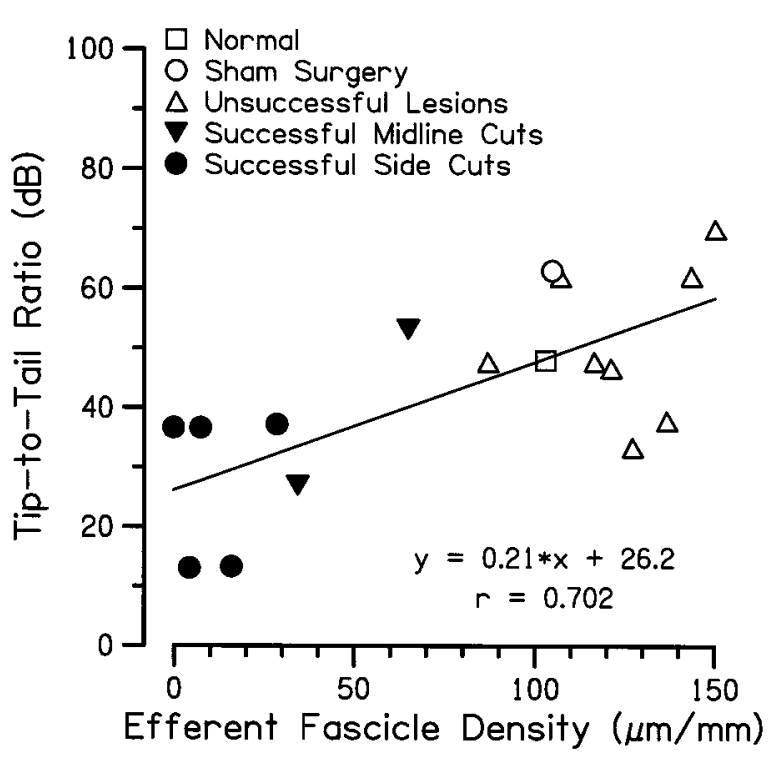

Figure 5. Tip-to-tail ratios averaged across CF (for fibers with CFs of $>5$ $\mathrm{kHz}$ ) are plotted as a function of the corresponding efferent fascicle densities, also averaged across cochlear location, for individual ears. Different symbols represent ears grouped into the various categories based on surgical outcome. A least squares linear regression was fitted to all values, and the parameters of the fit are shown. Tip-to-tail ratio is computed as defined in the legend to Figure 4. 


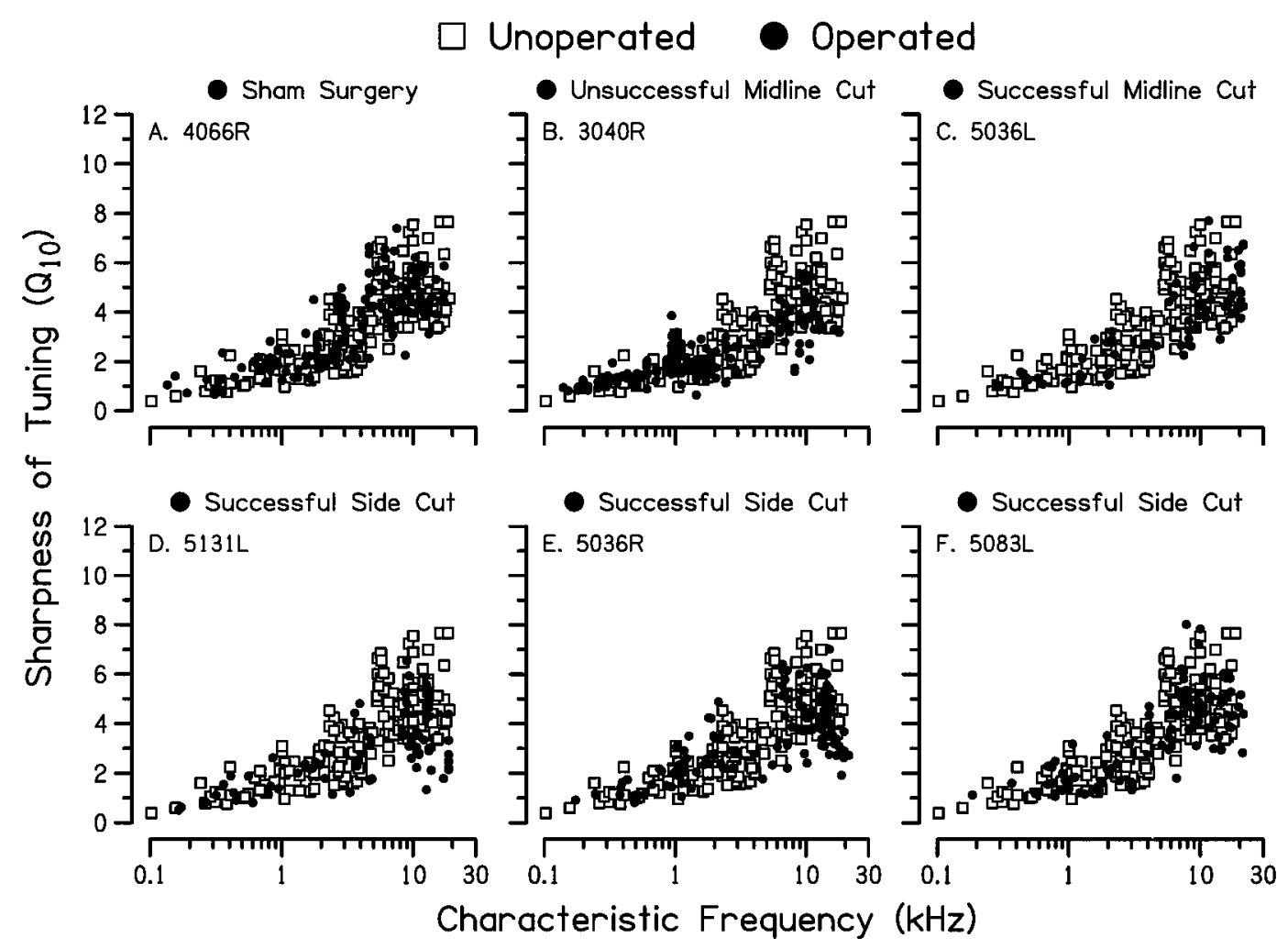

Figure 6. Tuning curve sharpness is plotted as a function of CF for the same set of animals shown in Figure 3. The measure of sharpness of tuning, $Q_{10}$, is computed as defined in Figure 4.

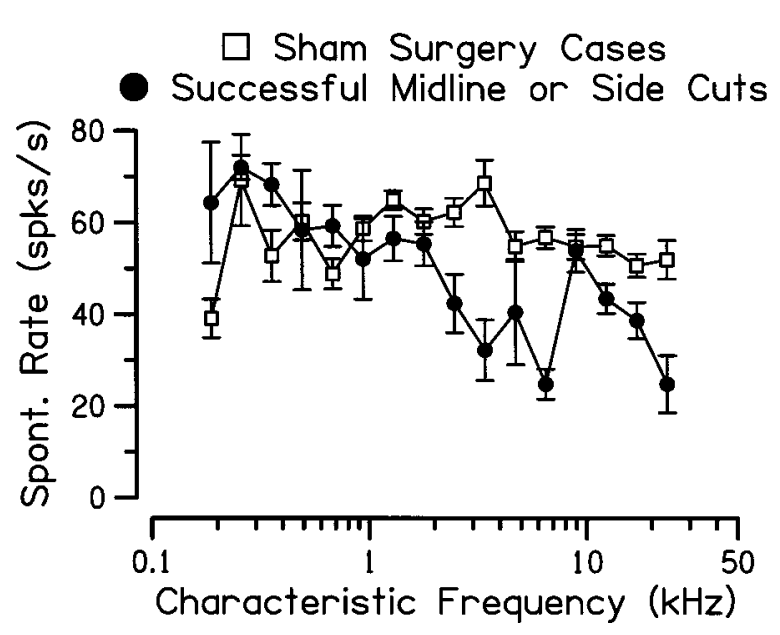

Figure 7. Comparison of average spontaneous rates for all animals in which successful side cuts were made and those animals undergoing the same surgical procedures in which the cut failed to transect the OCB. All high-SR fibers are divided, according to CF, into $\sim 0.5$-octave bins; values for all fibers are averaged and displayed \pm SEM.

1992a,b). In addition, OHCs, although equipped with stereocilia, do not contact the tectorial membrane. The final stages of maturation begin in a restricted area of the basal turn of the cochlea, and, although more advanced at birth, the basal turn of the cochlea remains immature (Lim, 1987).

At birth, the MOC system has already invaded the cochlea; however, neonatal MOC connections are restricted to the IHC area, rather than the OHC area as in the adult (Pujol et al., 1978,
1979; Simmons et al., 1990). LOC fibers appear to arrive later, forming adult-like synapses in the IHC area during the perinatal period. At this time, MOC fibers lose their connections in the IHC area and migrate across the tunnel of Corti (Pujol et al., 1978), ultimately forming synapses with OHCs at the time that OHCs begin expressing agents involved in neurotrophin and receptor interactions (Despres and Romand, 1994; Wheeler et al., 1994; Ernfors et al., 1995; Knipper et al., 1995, 1996). The OC system matures rapidly over the following 2 or 3 weeks (Pujol and Marty, 1970; Pujol et al., 1978, 1979, 1985; Lenoir et al., 1980; Shnerson et al., 1982; Simmons et al., 1990, 1996), paralleling the period of rapid functional maturation.

Cochlear afferent innervation also reorganizes during the first postnatal weeks. Type I and type II afferents, which in adults contact only IHCs or OHCs, respectively, contact both IHCs and OHCs in the neonate (Perkins and Morest, 1975; Echteler, 1992; Simmons, 1994). Many afferent OHC contacts disappear during the first two postnatal weeks, as efferents invade the OHC area (Pujol et al., 1978, 1985). Adult-like innervation patterns are observed by the end of the first postnatal month (Pujol et al., 1978).

Given the immature character of inner ear morphology, ANFs are insensitive to sound, tuning curves are broad, and SRs rarely exceed 10 spikes/sec (Romand, 1984; Dolan et al., 1985; Walsh and McGee, 1990; Walsh and Romand, 1992). Additionally, during the first postnatal week, sound-evoked ANF discharges are rhythmic in response to long-duration stimuli (Pujol, 1972; Walsh and McGee, 1987); this discharge regularity contrasts markedly with the random interspike intervals seen in adult ANFs (Kiang et al., 1965). This regular discharge requires an intact OCB, because its transection immediately eliminates bursting responses 


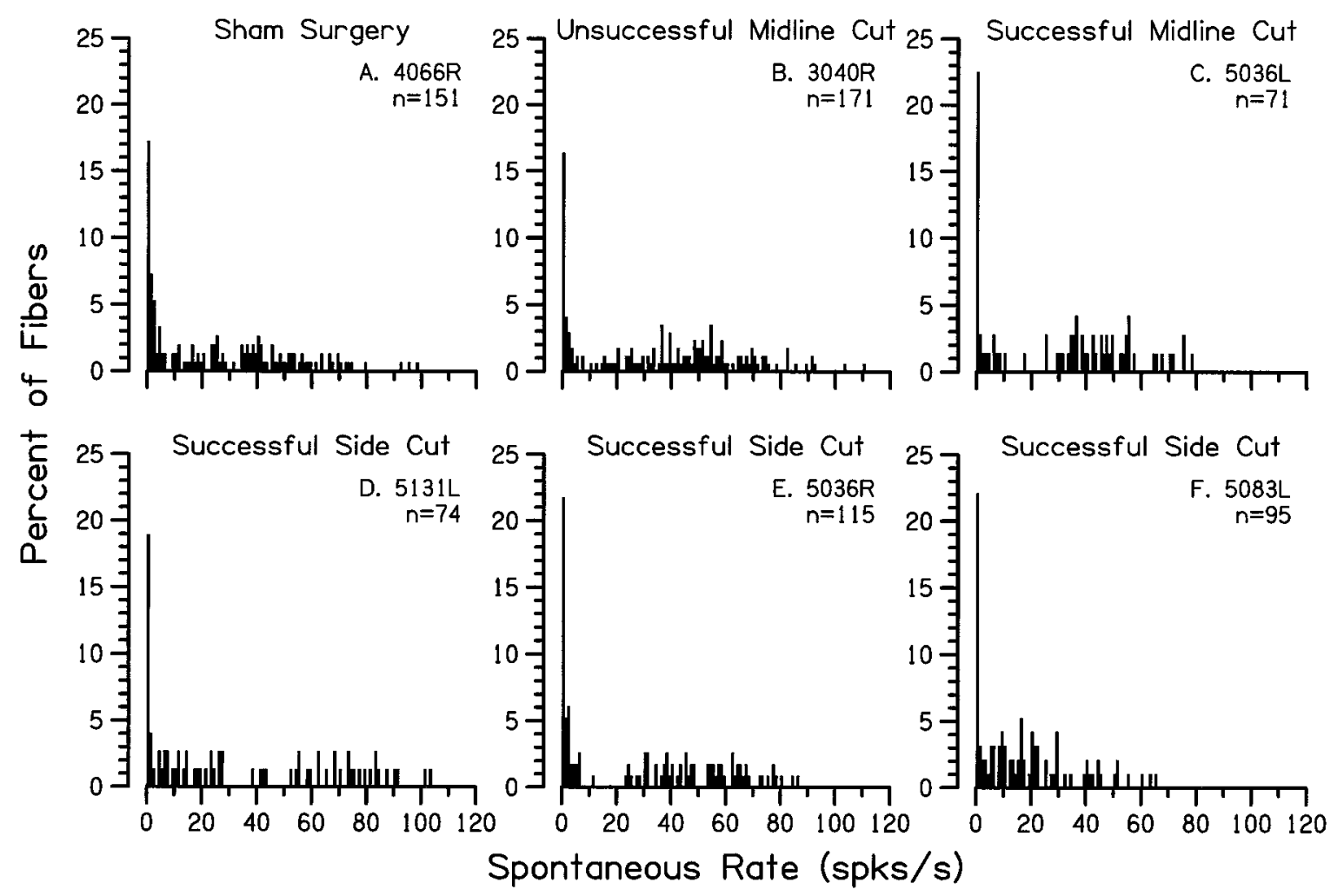

Figure 8. Distributions of spontaneous rate for the same set of animals shown in Figures 3 and 7 . Only fibers with $\mathrm{CFs}$ of $>1 \mathrm{kHz}$ are included in distributions.

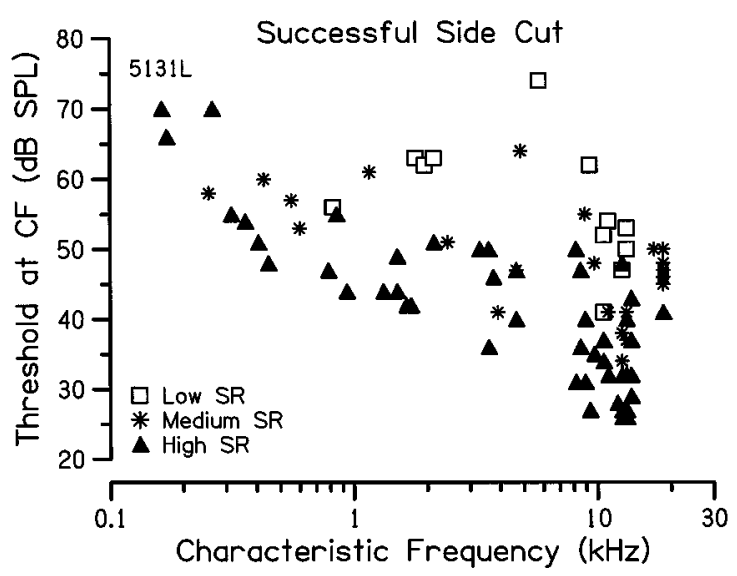

Figure 9. Scatter plot of thresholds at the CF for one totally deefferented case, plotted with different symbols for the three SR groups.

in cochlear nucleus neurons (Walsh et al., 1995; Walsh and McGee, 1997).

In adults, activation of the OC bundle suppresses the responses of ANFs to sound in quiet backgrounds, especially for tones near the CF (Wiederhold and Kiang, 1970). Such suppression is mediated via the MOC efferents to OHCs (Warren and Liberman, 1989). OCB function in the first postnatal week is difficult to assess, given the lack of acoustic responsiveness of ANFs. Carlier and Pujol (1976) reported that electrical stimulation of the OCB in kittens suppressed the compound action potential (CAP) "as soon as the acoustic stimulus is effective"; the youngest animal from which they show results is 9 d old. Similarly, the earliest age at which acoustic activation of the OCB via contralateral sound has been found to suppress ANF activity is P10 (Jenkins et al., 1993), supporting the notion that the OHC efferent system is not functional during the first postnatal week.

\section{Effects of chronic and acute deefferentation in adults} and neonates

In adult cats, complete cochlear deefferentation does not change the sensitivity or tuning characteristics of ANFs, whether performed acutely (Warren and Liberman, 1989; Liberman, 1991) or chronically (Liberman, 1990). The completeness of such lesions has been clearly demonstrated, both histologically (using retrograde tracer transport from the cochlea, AChE staining of the cochlea, or serial section electron microscopy) and functionally (using CAP suppression from electric shocks to the OCB). The notion that adult deefferentation should not affect threshold tuning of ANFs is consistent with known response properties of OC neurons (Liberman, 1988). Because OC neurons have little spontaneous activity and do not respond until sound pressure exceeds the thresholds of even the most insensitive ANFs (Liberman, 1988), transection of the OCB should not affect threshold-level responses of ANFs. Thus, the increases in ANF thresholds and decreases in sharpness of tuning observed in neonatally deefferented animals represent fundamental differences from the documented effects of adult deefferentation. Nevertheless, the fact that ANF responses recorded in the present study resemble those recorded from normal adults in certain aspects clearly demonstrates that many aspects of cochlear development can proceed normally in the complete absence of the OCB.

After chronic deefferentation in adult cats (Liberman, 1990), the only consistent ANF pathophysiology was compression of the SR distribution such that the mean SR of high-SR fibers was decreased from $\sim 70$ to 40 spikes/sec. This SR abnormality is very 
similar to that seen in the present study (Fig. 7), even with respect to the CF dependence; both adult and neonatally deefferented animals show the largest SR anomalies for CFs of $>1 \mathrm{kHz}$. It has been argued (Liberman, 1990) that this SR anomaly is caused by the loss of LOC rather than MOC innervation; however, the argument is based solely on the fact that LOC fibers synapse on afferent fibers and are thus positioned to affect SR, whereas MOC fibers are not. It is interesting that the SR distribution was closer to normal in our two cases of successful midline deefferentation; the midline lesion should eliminate most of the MOC system without a large effect on the LOC system (Warr, 1992). However, more data are needed on SR distributions subsequent to midline versus side cut lesion sites. The anatomical observation that low-SR fibers receive more LOC innervation than high-SR fibers (Liberman et al., 1990) suggested that the LOC system might establish or maintain the SR-based heterogeneity in ANFs. However, the present data (Fig. 9) show that the fundamental relation between SR and sensitivity develops normally in the absence of an LOC innervation. Thus, the function of the LOC system and the significance of its selective targeting of low-SR fibers remain enigmatic.

\section{Effects of neonatal deefferentation: OC-mediated protection from acoustic injury or OC-mediated control of normal development?}

The ANF pathophysiology we showed after neonatal deefferentation is similar to that seen in adults after cochlear insults, including ototoxic drugs (Kiang et al., 1970; Dallos and Harris, 1978) and acoustic trauma (Liberman and Kiang, 1978; Schmiedt et al., 1980). The particular constellation of abnormalities, including elevation of the tuning curve tip, decrease in tip-to-tail ratio, and decrease in sharpness of tuning, are characteristic of selective damage to the OHCs (Liberman and Dodds, 1984). Combining these results from pathological animals with recent studies of OHC motility (Brownell et al., 1985; Santos-Sacchi and Dilger, 1988; Hallworth et al., 1993) has suggested that normal OHCs amplify the mechanical motion of the cochlear partition for frequencies near the CF via voltage-dependent length or stiffness changes associated with the OHC system.

Thus, selective OHC damage in adults results in selective elevation of tuning curve tips and loss of many of the normal nonlinearities in cochlear response (Kiang et al., 1970; Dallos et al., 1980; Schmiedt and Zwislocki, 1980; Liberman and Dodds, 1984). Furthermore, during the developmental stage when most deefferentations were performed in this study, normal adult nonlinearities are not yet observed in the responses of ANFs (Walsh and McGee, 1987; Fitzakerley et al., 1994a-c; Song et al., 1995; Tubach et al., 1996) or in otoacoustic emission measurements in the cat (Tierney et al., 1994; Cihak et al., 1995). One interpretation of the present result is that $\mathrm{OHC}$ function, including the role as cochlear amplifier, fails to develop normally in the absence of an efferent innervation. Additional evidence that the primary dysfunction is in the OHCs is the observation (Walsh et al., 1998) that thresholds for distortion product otoacoustic emissions are elevated in our neonatally deefferented ears, similar to the threshold elevation for neural responses reported here. As outlined above, if the OCB is successfully transected in $\mathrm{P} 1-\mathrm{P} 4$, the OC system never reaches the $\mathrm{OHC}$ area. Although the $\mathrm{OHCs}$ are present in the deefferented ears to the same extent as in their sham-operated cohorts (Fig. 2), the neonatal loss of the OCB might lead to overexpression or underexpression of a component key to the $\mathrm{OHC}$ amplification process. This finding is consistent with the view that an essential, possibly trophic, interaction between the OCB and OHCs is required for the normal development of hearing.

An alternative explanation is that the putative OHC dysfunction arises from a heightened susceptibility to acoustic injury. In adult animals, activation of the OCB during an acoustic overexposure can decrease acute threshold shifts in anesthetized animals (Rajan, 1988a,b, 1995; Reiter and Liberman, 1995), and chronic deefferentation increases the vulnerability of the ear to permanent acoustic injury (Handrock and Zeisberg, 1982; Liberman and Gao, 1995; Zheng et al., 1997a,b). Moreover, the cochlea appears to be hypersensitive, during "critical" developmental periods, to a variety of insults, including (1) sound exposure (Douek et al., 1976; Bock and Saunders, 1977; Lenoir and Pujol, 1980; Uziel, 1985), (2) ototoxic aminoglycosides and loop diuretics (Uziel et al., 1979; Carlier and Pujol, 1980; Raphael et al., 1983), and (3) pathological conditions such as hypothyroidism (Deol, 1976; Uziel et al., 1983) (P. M. Sprenkle, E. J. Walsh, J. McGee, and J. M. Bertoni, unpublished results). One critical period occurs just before the onset of function, and the other coincides with the rapid acquisition of function; the latter clearly overlaps with the period of rapid reorganization of the efferent innervation of the cochlea. The only evidence of cochlear trauma noted in this study was the loss of basal turn OHCs in both unsuccessful and successful surgical cases. The cause of OHC loss is unknown.

Although our animals were not purposefully overexposed, deefferentation during a "critical" period could render the routine noise levels in the vivarium traumatic to the ear. The strongest argument against this interpretation is that, under those conditions, the degree of threshold shift observed in this study ( $>60 \mathrm{~dB}$ in some cases) would always be correlated with severe and widespread stereocilia damage and outer hair cell loss in adult animals with noise-induced threshold shifts (Liberman and Kiang, 1978; Liberman and Dodds, 1984). Although a quantitative evaluation of stereocilia condition was not performed, qualitative analysis suggests that no such disarray is present in our animals. Collectively, these findings support the conclusion that neonatal deefferentation interferes with the development of normal cochlear function.

\section{REFERENCES}

Bock GR, Saunders JC (1977) A critical period for acoustic trauma in the hamster and its relation to cochlear development. Science 197:396-398.

Brown MC (1987) Morphology of labeled efferent fibers in the guinea pig cochlea. J Comp Neurol 260:605-618.

Brown MC, Nuttall AL, Masta RI (1983) Intracellular recordings from cochlear inner hair cells: effects of stimulation of the crossed olivocochlear efferents. Science 222:69-72.

Brownell WE, Bader CR, Bertrand D, deRibaupierre Y (1985) Evoked mechanical response of isolated cochlear outer hair cells. Science 277:194-196.

Carlier E, Pujol R (1976) Early effects of efferent stimulation on the kitten cochlea. Neurosci Lett 3:21-27.

Carlier E, Pujol R (1980) Supra-normal sensitivity to ototoxic antibiotics of the developing rat cochlea. Arch Otorhinolaryngol 226:129-133.

Cihak R, McGee J, Walsh EJ (1995) The development of otoacoustic emissions. Am Laryngol Rhinol Otol Soc Abstr.

Dallos P, Harris DM (1978) Properties of auditory nerve responses in the absence of outer hair cells. J Neurophysiol 41:365-383.

Dallos P, Harris DM, Relkin E, Cheatham MA (1980) Two-tone suppression and intermodulation distortion in the cochlea: effect of outer hair cell lesions. In: Psychophysical, physiological, and behavioral studies in hearing (van den Brink G, Bilsen FA, eds), pp 242-249. Delft, Amsterdam: Delft University. 
Deol MS (1976) Deficiencies of the inner ear in the mouse and their origin. Colloq Int Cent Natl Rech Sci 266:63-171.

Despres G, Romand R (1994) Neurotrophins and the development of cochlear innervation. Life Sci 54:1291-1297.

Dewson JH (1968) Efferent olivocochlear bundle: some relationships to stimulus discrimination in noise. J Neurophysiol 31:122-130.

Dolan DF, Teas DC, Watson JP (1985) Postnatal development of physiological responses in auditory nerve fibers. J Acoust Soc Am 78:544-554.

Douek E, Dodson HC, Bannister LH, Ashcroft P, Humphries KN (1976) Effects of incubator noise on the cochlea of the newborn. Lancet 20:1110-1113.

Echteler SM (1992) Developmental segregation in the afferent projections to mammalian auditory hair cells. Proc Natl Acad Sci USA 89:6324-6327.

Ernfors P, Van De Water T, Loring J, Jaenisch R (1995) Complementary roles of BDNF and NT-3 in vestibular and auditory development. Neuron 14:1153-1164.

Fitzakerley JL, McGee J, Walsh EJ (1994a) Responses of peripheral auditory neurons to two-tone stimuli during development. I. Correlation with frequency selectivity. Hear Res 77:135-149.

Fitzakerley JL, McGee J, Walsh EJ (1994b) Responses of peripheral auditory neurons to two-tone stimuli during development. II. Relationship with neural response properties. Hear Res 77:150-161.

Fitzakerley JL, McGee J, Walsh EJ (1994c) Responses of peripheral auditory neurons to two-tone stimuli during development. III. Rate facilitation. Hear Res 77:162-167.

Ginzberg RD, Morest DK (1984) Fine structure of cochlear innervation in the cat. Hear Res 14:104-127.

Guinan Jr JJ (1996) Physiology of olivocochlear efferents. In: The cochlea (Dallos P, Popper AN, Fay RR, eds), pp 435-502. New York: Springer.

Guinan Jr JJ (1986) Effects of efferent neural activity on cochlear mechanics. Scand Audiol Suppl 25:53-62.

Guinan Jr JJ, Warr WB, Norris BE (1983) Differential olivocochlear projections from lateral versus medial zones of the superior olivary complex. J Comp Neurol 221:358-370.

Hallworth R, Evans BN, Dallos P (1993) The location and mechanism of electromotility in guinea pig outer hair cells. J Neurophysiol 70:549-558.

Handrock M, Zeisberg J (1982) The influence of the efferent system on adaptation, temporary and permanent threshold shift. Arch Otorhinolaryngol 234:191-195.

Igarashi M, Alford BR, Nakai Y, Gordon WP (1972) Behavioral auditory function after transection of crossed olivo-cochlear bundle in the cat. I. Pure-tone threshold and perceptual signal-to-noise ratio. Acta Otolaryngol (Stockh) 73:455-466.

Jenkins JJ, McGee J, Walsh EJ (1993) Developmental changes of auditory nerve responses to efferent stimulation. Soc Neurosci Abstr 23:534.

Jones DG, Eslami H (1983) An ultrastructural study of the development of afferent and efferent synapses on outer hair cells of the guinea pig organ of Corti. Cell Tissue Res 231:533-549.

Kawase T, Liberman MC (1993) Anti-masking effects of the olivocochlear reflex. I. Enhancement of compound action potentials to masked tones. J Neurophysiol 70:2519-2532.

Kiang NYS, Watanabe T, Thomas EC, Clark LF (1965) Discharge patterns of single fibers in the cat's auditory nerve. Cambridge, MA: MIT.

Kiang NYS, Moxon EC, Levine RA (1970) Auditory-nerve activity in cats with normal and abnormal cochleas. In: Sensorineural hearing loss (Wolstenholme GEW, Knight J, eds), pp 241-267. London: Churchill.

Knipper M, Zimmermann U, Rohbock K, Kopschall I, Zenner HP (1995) Synaptophysin and GAP-43 proteins in efferent fibers of the inner ear during postnatal development. Dev Brain Res 89:73-86.

Knipper M, Zimmermann U, Rohbock K, Kopschall I, Zenner HP (1996) Expression of neurotrophin receptor trkB in rat cochlear hair cells at time of rearrangement of innervation. Cell Tissue Res 283:339-353

Kraus HJ, Aulbach-Kraus K (1981) Morphological changes in the cochlea of the mouse after the onset of hearing. Hear Res 4:89-102.

Lenoir M, Pujol R (1980) Sensitive period to acoustic trauma in the rat pup cochlea. Histological findings. Acta Otolaryngol (Stockh) 89:317-322.

Lenoir M, Shnerson A, Pujol R (1980) Cochlear receptor development in the rat with emphasis on synaptogenesis. Anat Embryol 160:253-262.
Liberman MC (1978) Auditory nerve response from cats raised in a low-noise chamber. J Acoust Soc Am 63:442-455.

Liberman MC (1982) Single-neuron labelling in the cat auditory nerve. Science 216:1239-1241.

Liberman MC (1988) Physiology of cochlear efferent and afferent neurons: direct comparisons in the same animal. Hear Res 34:179-192.

Liberman MC (1990) Effects of chronic cochlear de-efferentation on auditory-nerve response. Hear Res 49:209-224.

Liberman MC (1991) The olivocochlear efferent bundle and susceptibility of the inner ear to acoustic injury. J Neurophysiol 65:123-132.

Liberman MC, Dodds LW (1984) Single-neuron labeling and chronic cochlear pathology. III. Stereocilia damage and alterations of threshold tuning curves. Hear Res 16:55-74.

Liberman MC, Gao W-Y (1995) Chronic cochlear de-efferentation and susceptibility to permanent acoustic injury. Hear Res 90:158-168.

Liberman MC, Kiang NYS (1978) Acoustic trauma in cats: cochlear pathology and auditory nerve activity. Acta Otolaryngol Suppl (Stockh) 358:1-63.

Liberman MC, Dodds LW, Pierce S (1990) Afferent and efferent innervation of the cat cochlea: quantitative analysis with light and electron microscopy. J Comp Neurol 301:443-460.

Lim DJ (1987) Development of the tectorial membrane. Hear Res 28:9-21.

Lindeman HH, Ades HW, Bredberg G, Engstrom H (1971) The sensory hairs and the tectorial membrane in the development of the cat's organ of Corti. Acta Otolaryngol (Stockh) 72:229-242.

May BJ, McQuone SJ (1995) Effects of bilateral olivocochlear efferent lesions on pure-tone intensity discrimination in cats. Aud Neurosci 1:385-400.

Mountain DC (1980) Changes in endolymphatic potential and crossed olivocochlear bundle stimulation alter cochlear mechanics. Science 210:71-72.

Murugasu E, Russell IJ (1996) The effect of efferent stimulation on basilar membrane displacement in the basal turn of the guinea pig cochlea. J Neurosci 16:325-332.

Perkins RE, Morest DK (1975) A study of cochlear innervation patterns in cats and rats with the Golgi method and Nomarski optics. J Comp Neurol 163:129-158.

Pujol R (1972) Development of tone-burst responses along the auditory pathway in the cat. Acta Otolaryngol (Stockh) 74:383-391.

Pujol R, Abonnenc M (1977) Receptor maturation and synaptogenesis in the golden hamster cochlea. Arch Otorhinolaryngol 217:1-12.

Pujol R, Carlier E (1982) Cochlear synaptogenesis after sectioning the efferent bundle. Dev Brain Res 3:151-154.

Pujol R, Marty R (1970) Postnatal maturation in the cochlea of the cat. J Comp Neurol 139:115-126.

Pujol R, Carlier E, Devigne C (1978) Different patterns of cochlear innervation during the development of the kitten. J Comp Neurol 177:529-536.

Pujol R, Carlier E, Devigne C (1979) Significance of presynaptic formations in early stages of cochlear synaptogenesis. Neurosci Lett 15:97-102.

Pujol R, Lenoir M, Robertson D, Eybalin M, Johnstone BM (1985) Kainic acid selectively alters auditory dendrites connected with cochlear inner hair cells. Hear Res 18:145-151.

Rajan R (1988a) Effect of electrical stimulation of the crossed olivocochlear bundle on temporary threshold shifts in auditory sensitivity. II. Dependence on the level of temporary threshold shifts. J Neurophysiol 60:569-579

Rajan R (1988b) Effect of electrical stimulation of the crossed olivocochlear bundle on temporary threshold shifts in auditory sensitivity. I. Dependence on electrical stimulation parameters. J Neurophysiol 60:549-568

Rajan R (1995) Involvement of cochlear efferent pathways in protective effects elicited with binaural loud sound exposure in cats. J Neurophysiol 74:582-597.

Raphael Y, Fein A, Nebel L (1983) Transplacental kanamycin ototoxicity in guinea pigs. Arch Otorhinolaryngol 238:45-51.

Reiter ER, Liberman MC (1995) Efferent-mediated protection from acoustic overexposure: relation to slow effects of olivocochlear stimulation. J Neurophysiol 73:506-514.

Romand R (1984) Functional properties of auditory-nerve fibers during postnatal development in the kitten. Exp Brain Res 56:395-402.

Roth B, Bruns V (1992a) Postnatal development of the rat organ of 
Corti. I. General morphology, basilar membrane, tectorial membrane and border cells. Anat Embryol 185:559-569.

Roth B, Bruns V (1992b) Postnatal development of the rat organ of Corti. II. Hair cell receptors and their supporting elements. Anat Embryol 185:571-581.

Santos-Sacchi J, Dilger JP (1988) Whole cell currents and mechanical responses of isolated outer hair cells. Hear Res 35:143-150.

Scharf B, Magnan J, Collet L, Ulmer E, Chays A (1994) On the role of the olivocochlear bundle in hearing: a case study. Hear Res 75:11-26.

Schmiedt RA, Zwislocki JJ (1980) Effects of hair cell lesions on responses of cochlear nerve fibers. II. Single- and two-tone intensity functions in relation to tuning curves. J Neurophysiol 43:1390-1405.

Schmiedt RA, Zwislocki JJ, Hamernik RP (1980) Effects of hair cell lesions on responses of cochlear nerve fibers. I. Lesions, tuning curves, two-tone inhibition, and responses to trapezoidal-wave patterns. J Neurophysiol 43:1367-1389.

Shnerson A, Devigne C, Pujol R (1982) Age-related changes in the C57BL/6J mouse cochlea. II. Ultrastructural findings. Dev Brain Res 2:77-88.

Siegel JH, Kim DO (1982) Efferent neural control of cochlear mechanics? Olivocochlear bundle stimulation affects cochlear biomechanical nonlinearity. Hear Res 6:171-182.

Simmons DD (1994) A transient afferent innervation of outer hair cells in the postnatal cochlea. NeuroReport 5:1309-1312.

Simmons DD, Manson-Gieseke L, Hendrix TW, McCarter S (1990) Reconstructions of efferent fibers in the postnatal hamster cochlea. Hear Res 49:127-140.

Simmons DD, Mansdorf NB, Kim JH (1996) Olivocochlear innervation of inner and outer hair cells during postnatal maturation: evidence for a waiting period. J Comp Neurol 370:551-562.

Song L, McGee J, Walsh EJ (1995) Furosemide effects on two-tone suppression areas of immature and adult auditory nerve fibers. Soc Neurosci Abstr 21:397.

Sridhar TS, Liberman MC, Brown MC, Sewell WF (1995) A novel cholinergic "slow effect" of olivocochlear stimulation on cochlear potentials in the guinea pig. J Neurosci 15:3667-3678.

Tierney TS, McGee J, Walsh EJ (1994) Development of cubic distortion product otoacoustic emissions in the cat. Assoc Res Otolaryngol Abstr 17:50.

Trahiotis C, Elliott DN (1970) Behavioral investigation of some possible effects of sectioning the crossed olivocochlear bundle. J Acoust Soc Am 47:592-596.

Tubach M, McGee J, Walsh EJ (1996) Distortion generated by the ear: its emergence and evolution during development. Laryngoscope 106:822-830.

Uziel A (1985) Nongenetic factors affecting hearing development. Acta Otolaryngol Suppl (Stockh) 421:57-61.

Uziel A, Romand R, Marot M (1979) Electrophysiological study of the ototoxicity of kanamycin during development in guinea pigs. Hear Res 1:203-211.

Uziel A, Legrand C, Ohresser M, Marot M (1983) Maturational and degenerative processes in the organ of Corti after neonatal hypothyroidism. Hear Res 11:203-218.
Walsh EJ, McGee J (1986) The development of function in the auditory periphery of cats. In: Neurobiology of hearing: the cochlea (Altschuler RA, Bobbin RP, Hoffman DW, eds), pp 247-269. New York: Raven.

Walsh EJ, McGee J (1987) Postnatal development of auditory nerve and cochlear nucleus neuronal responses in kittens. Hear Res 28:97-116.

Walsh EJ, McGee J (1988) Rhythmic discharge properties of caudal cochlear nucleus neurons during postnatal development in cats. Hear Res 36:233-248.

Walsh EJ, McGee J (1990) Frequency selectivity in the auditory periphery: similarities between damaged and developing ears. Am J Otolaryngol 11:23-32.

Walsh EJ, McGee J (1997) Does activity in the olivocochlear bundle affect development of the auditory periphery? In: Diversity in auditory mechanics (Lewis ER, Long GR, Lyon RF, Narins PM, Steele CR, Hecht-Poinar E, eds), pp 376-385. Singapore: World Scientific.

Walsh EJ, Romand R (1992) Functional development of the cochlea and the cochlear nerve. In: Development of auditory and vestibular systems 2 (Romand R, ed), pp 161-219. Amsterdam: Elsevier.

Walsh EJ, McGee J, Lackey J (1995) Acute lesions of the olivocochlear bundle eliminate sound-evoked discharge rhythmicity of immature auditory neurons. Soc Neurosci Abstr 21:127.

Walsh EJ, McGee J, Song L, Liberman MC (1998) Consequences of neonatal OCB transection on the expression of peripheral auditory nonlinearities. Assoc Res Otolaryngol Abstr 21:214.

Warr WB (1975) Olivocochlear and vestibular efferent neurons of the feline brain stem: their location, morphology and number determined by retrograde axonal transport and acetylcholinesterase histochemistry. J Comp Neurol 161:159-182.

Warr WB (1992) Organization of olivocochlear efferent systems in mammals. In: The mammalian auditory pathway: neuroanatomy (Webster DB, Popper AN, Fay RR, eds), pp 410-448. New York: Springer.

Warr WB, Guinan Jr JJ (1979) Efferent innervation of the organ of Corti: two separate systems. Brain Res 173:152-155.

Warren III EH, Liberman MC (1989) Effects of contralateral sound on auditory-nerve responses. I. Contributions of cochlear efferents. Hear Res 37:89-104.

Wheeler EF, Bothwell M, Schecterson LC, von Bartheld CS (1994) Expression of BDNF and NT-3 mRNA in hair cells of the organ of Corti: quantitative analysis in developing rats. Hear Res 73:46-56.

Wiederhold ML, Kiang NYS (1970) Effects of electric stimulation of the crossed olivocochlear bundle on single auditory nerve fibers in the cat. J Acoust Soc Am 48:950-965.

Winslow RL, Sachs MB (1988) Single-tone intensity discrimination based on auditory-nerve rate responses in backgrounds of quiet, noise, and with stimulation of crossed olivocochlear bundle. Hear Res 35:165-190.

Zheng XY, Henderson D, McFadden SL, Hu B-H (1997a) The role of the cochlear efferent system in acquired resistance to noise-induced hearing loss. Hear Res 104:191-203.

Zheng XY, Henderson D, Hu B-H, Ding D-L, McFadden SL (1997b) The influence of the cochlear efferent system on chronic acoustic trauma. Hear Res 107:147-159. 